\section{Liver - general}

\section{OXIX/1965}

Ultrasound assisted ambulatory percutaneous liver biopsy;

a report on two-thousand cases.

Judmaier G., Prior Chr., Propst A., Vogel W., Kathrein H.*

Department of Internal Medicine

Division of Gastroenterology and Hepatology, *Ultrasound Lab. Innsbruck/Austria

\section{Objective:}

We report on 2000 "ultrasonically-guided" percutaneous liver biopsies in outpatients. 1200 biopsies were performed by Menghini, 800 by Trucut needle. The risk of the procedure was compared between the two groups and the ultrasound investigation was evaluated for its effectiveness.

\section{Methods:}

The puncture site was marked based on sonographic findings, excluding cysts, metastases and haemangiomas. The gallbladder was localised and the maximal depth of puncture recorded. Biopsy was performed in standard technique under local anaesthesia. After biopsy, pain, blood pressure and clinical status were recorded for three hours. Ultrasound investigations were performed (Hitachi EUB 340, Diasonics-Spectra, Diasonics-Prisma, 3,5 and 5 Megahertz) after two and three hours.

\section{Results:}

Within ten years, more than 2000 patients were biopsied. There were no serious complications requiring operations, transfusions, or volume replacement. Slight complications were treated symptomatically. Seven patients were admitted for 24 hours because ultrasonography had revealed traces of intraabdominal fluid. Haematoma after puncture was a rare event ( 24 cases). There were no differences in the complication rate between the Menghini and the Trucut group.

\section{Conclusions:}

Sonographically guided percutaneous liver biopsy can be judged safe even in outpatients. Every hepatology unit should be equipped with an ultrasound scanner to minimize the risk of this procedure. Only typical puncture sites marked under sonographic guidance should be used. Since tissue yield of the Trucut needle is better and risk is not increased this needle should be preferred.

\section{OXIX/2 220}

ORAL SODIUM BENZOATE IN THE TREATMENT OF CHRONIC HEPATIC ENCEPHALOPATHY

C. Panella, F.W. Guglielmi, T. Mastronuzzi, F. Contento, N. Siciliano, A. Francavilla Department of Gastroenterology, University of Bari, Italy

Sodium benzoate (SB) is a widely used food preservative that have been shown to be effective in the treatment of hyperammoniemia associated with congenital urea cycle enzymopathies. SB promote amino acid acylation products that could be used to increase urinary nitrogen excretion. Although tew studies report beneficial effects of $S B$ compared to lactulose or neomycin in cirrhotic patients with chronic of SB compared to lactulose or neomycin in cirrhotic patients with chronic $S B$ on the therapeutic effects of oral branched chain amino acids (BCAA).

In this double-blind cross-over study we investigate, in 7 cirrhotic patients with stable encephalopathy (I-III grade) the role of SB to lower ammonia and portal systemic encephalopathy index (PSE). The patients received an hospital diet (30 $\mathrm{KCalkg} / \mathrm{die}, 40 \mathrm{~g}$ of protein) supplemented with BCAA (24g/day); lactulose (10-60 $\mathrm{g} /$ day) or colimicin (6 MU/day) were added as standard therapy. After 7 days they were randomly divided in two groups. In each group $10 \mathrm{~g} /$ day of $\mathrm{SB}$ or $10 \mathrm{~g} /$ day of placebo (PI), were added for other 7 days. Subsequently the treatments were reversed and patients were screened finally after 7 days. Liver function tests were studied to select patients; venous ammonia levels $\left(\mathrm{NH}_{4}{ }^{+}\right)$, number connection test (NCT) and PSE were monitored at baseline and the 7 th, 14th, 21st and 28 th days of treatment; plasma and urinary levels of $\mathrm{Na}+$ were detected daily. In the table we report our results:

\begin{tabular}{lccr}
\hline & $\mathrm{NH}_{4}{ }^{+}(\mathrm{g} / \mathrm{d} 1)$ & $\mathrm{NCT}$ & \multicolumn{1}{c}{ PSE } \\
\hline BaselIDe & $124 \pm 64$ & $200 \pm 113$ & $10.0 \pm 3.0$ \\
BCAA & $140 \pm 44$ & $202 \pm 167$ & $8.0 \pm 3.7$ \\
BCAA+SB & $84 \pm 4 *$ & $127 \pm 072$ & $6.8 \pm 3.8$ \\
BCAA+P1 & $151 \pm 76$ & $142 \pm 094$ & $8.0 \pm 3.4$ \\
\hline
\end{tabular}

Our data show that in cirrhotic patients with chronic encephalopathy treated with $B C A A, S B$ is able to induce, compared to placebo, a significant reduction of $\mathrm{NH}_{4}{ }^{+}$ together with a down trend of NCT and PSE values.

\section{OXIX/3938}

13C-AMINOPYRINE BREATH TEST: A SIMPLE AND HIGHLY SENSITIVE TEST FOR ASSESSMENT OF LIVER DYSFUNCTION

PE Queneau, F Mion, M Rousseau*, JL Brazierº, P Paliard, Y Minaire. Fédération des Spécialités Digestives, Hospital E. Herriot, Lyon, France.

$14 \mathrm{C}$-aminopyrine breath test (ABT) is known as a reliable test for evaluation of liver metabolic function. However, its use is limited because of its radioactivity. The goal of our study was to validate a $13 \mathrm{C}$-ABT for clinical use.

Mlaterial and methods. $2 \mathrm{mg} / \mathrm{Kg} 13 \mathrm{C}$-aminopyrine were given orally and breath samples were obtained 10 minutes before $\left(t-10^{\prime}\right)$, at $t+60^{\prime}$, and every 30 minutes until $t+210$ ' thereafter. $13 \mathrm{CO} 2$ enrichment of breath samples was measured using a new on-line GC-IRMS device. This technique allows the analysis of small volumes with low $13 \mathrm{C}$ enrichments. healthy volunteers and 23 cirrhotic patients. The most discriminant parameters were found to be the $13 \mathrm{CO} 2$ enrichment at $t+60^{\prime}$ ( Dif $60-0$ ), and $\mathrm{R}=\mathrm{AUC} / \mathrm{dose}$. There was a very strong correlation between these two parameters, both in controls and patients $\left(\mathrm{r}^{2}=0.92\right)$. The mean value $( \pm S D)$ of Dif $60-0$ was $10.7 \pm 1.2$ delta\%o for the controls and $4.4 \pm 3.7$ delta\%o for the patients $(p<0.0001)$. Since the results obtained after 210 minutes were strongly correlated to the value of $\mathrm{Dif} 60-0$, i: was decided to use a measure Dif 60-0. The results were then analysed in 83 patients with liver disease, consisting in 68 cirrhosis ( 37 alcoholic, 23 viral hepatitis, 8 miscellaneous), and 15 non cirrhosis. A galactose elimination capacity test (GEC) was simultaneously performed. Amoung cirrhotic patients, 23 were Child A, 26 Child B and 19 Child C. The 13C-ABT was able to significantly discriminate non-cirrhotic and cirrhotic Child $A$ patients $(8.78 \pm 5.3$ vs $4.94 \pm 3.2, \quad p<0.05$ ) and to separate Child A from Child B/C patients $(4.94 \pm 3.25$ vs $2.59 \pm 1.51$ and $1.43 \pm 1.13$ respectively, $p<0.05)$. GEC allowed discrimination between Child $A$ and Child $B / C$ patients $(1.71 \pm 0.37$ vs $1.26 \pm 0.51$ and $1.09 \pm 0.28$ respectively, $p<0.05$ ), but not between cirrhotic and non cirrhotic patients $(1.62 \pm 0.38$ vs $1.71 \div 0.37)$ Furthermore C13-ABT was better correlated with the Child score than GEC $\left(r^{2}=0.327\right.$ vs $\left.r^{2}=0.227\right)$ Interestingly, three day-phenobarbital induction $(100 \mathrm{mg} / \mathrm{day})$ increased significantly the results of the ABT when the initial Dif $60-0$ value was greater than 4 delta\%o $(p<0.05)$. However, phenobarbital induction did not have any effect on ABT results when the initial Dif 60-0 was less than delta'cc. Alcoholic and non alcoholic cirrhosis formed comparable groups; $A B^{\prime} T$ was not statistically different in the two groups.

Conclusions. 13C-ABT is a simple, sensitive, and non invasive test for assessment of liver dysfunction. Its use seems particularly adapted to the detection and the follow-up of patients with minor liver diseases. *INBIOMED, Lyon, ${ }^{\circ} \mathrm{LEACM}, \mathrm{Lyon}$

Results. The relevant parameters of the 13C-ABT were first tested in 26 simplified $13 \mathrm{C}$ ABT, with only 2 breath samples at $t-10^{\prime}$ and $t+60^{\prime}$, to

\section{OXIX/4 1049}

A Randomized Controlled Clinical Trial of Medical Treatment vs Medicial Treatment plus Puncture in Amoebic Liver Abscess.

Arredondo-Cortes E.. MD, González-González J. A., MD, Bosques- Padilla Fco. MD, MSc, Elizondo Riojas G., MD, Barragin-Villarreal R. F., MD. University Hospital Dr. José E. González U.A.N.L., Monterrey, México. CP 64460.

Ohjectives: In order to compare the efficacy of two treatment modalities of amoebic liver abscess ( $A L A$ ) with regard to cure, hospital stay and need of surgery. Methods: We included patients older than 18 years with right upper cuadran abdominal pain, fever, increased WBC and US consistent with ALA. Patients with pleuropulmonary and pericardial complications, severe liver failure, abdominal guarding, shock or previous medical treatment for ALA were excluded. We randomized 15 patients to either traditional medical therapy (MTx) consistung in metronidazol $750 \mathrm{mg}$ IV tid and dehidroemetine $1-1.5 \mathrm{mg} / \mathrm{kg}$ iday IM or MTX plus US guided abscess puncture (MTX $+\mathrm{P}$ ) within the tirst $24 \mathrm{hrs}$ of admission Treatment was successful if the patient had no fever, a decrease in WBC $\geq 30 \%$ and the pain decreased $\geq 70 \%$ using an analog visuai scale at 72 hrs of admission (2 of 3 ) and had no complications.

Results: They are shown in the table below and are expressed as mean and SD and were analyzed using Student's T test, $95 \% \mathrm{CI}$ for the difference (@) and relative risk (RR) and the Fisher Exact test as appropriate and considered significant if $\mathrm{p} \leq$ 0.05 (two tailed).

\begin{tabular}{|c|c|c|c|c|}
\hline VARIABLE & $.47 \times(u=11)$ & $M T x+P(u=11)$ & SIGNIFICANCE & @ and RR IC $95 \%$ \\
\hline $\operatorname{Sex}(N / F)$ & $10 / 1$ & $10 / 1$ & is & \\
\hline Age (years) & $37.8 \pm 13.7$ & $33 \pm 8.6$ & is & \\
\hline Tetuperature $\left({ }^{\circ} \mathrm{C}\right)$ & $37.8 \pm 0.9$ & $37.9=0.7$ & is & \\
\hline Pain ( mw) & $7.4 \pm 3$ & $7.4 \pm 2$ & is & \\
\hline $\mathrm{WBC}$ & 16536 土 6524 & $16500 \pm 4775$ & is & \\
\hline Abuasin (gr/dl) & $2.6 \pm 0.3$ & $2.6 \pm 0.8$ & is & \\
\hline $\begin{array}{l}\text { Tot:al Bilinutinin } \\
\text { (ming/(II) }\end{array}$ & $1.6=1.2$ & $1.4 \pm 1.06$ & is & \\
\hline$A L P(I L / L)$ & $204 \pm 102$ & $151 \pm 56$ & NS & \\
\hline ALT (IU/I.) & $62 \pm 46$ & $50 \pm 26$ & is & \\
\hline Abscess size (cau ) & $7.9 \pm 1.8$ & $7.3 \pm 3$ & vS & \\
\hline IInspital stay (days) & $7.2+3.5$ & $4+0.6$ & $p=0.007$ & @ $3.2(1105.5)$ \\
\hline Treatment Fonilure & 8 & 0 & $p=0.001$ & RR 0.2110 .07 to 0.581 \\
\hline
\end{tabular}

Of the eleven patients in the .MTx group, 8 were submitted to a puncture because they failed to respond to treatment and their hospitalization time post-puncture was of $3.6 \pm 1.2$ days. No complications were reported in the 19 patients punctured. Conclusions: The hospitalization time of the MTx $+P$ group was less than MTX (difference $3.2[1.5-5.5])$. No patients needed surgery. Our results suggest that $M T x+P$ is superior to MTX alone in the tratment of ALA, hecasue it reduces hospitalization time, and the puncture in the patients who failed to MTx avoids surgery. 


\section{OXIX/5 246}

CIRCULATING ENZYME ACTIVITIES OF COLLAGEN TURNOVER AND UNDULIN IN PATIENTS WITH VARIOUS SEVERITY OF SCHISTOSOMIASIS AND ALCOHOLIC LIVER CIRRHOSIS. M. Shahin, D. Schuppan, R. Waldherr, E.R. Savolainen,

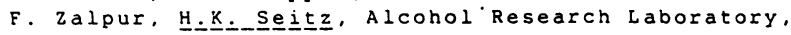

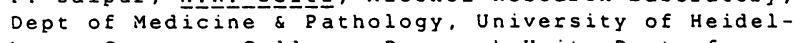
berg, Germany: Collagen Research Unit, Dept of Medical Biochemistry, University of Oulu, Finland

Schistosomiasis in contrast to alcoholic liver disease leads to presinusoidal hepatic fibrosis which determines the prognosis of the disease. Since conventional liver function tests and liver biopsy provide little information on the dynamics of the Fibzotic process, we measured the activities of two circulating enzymes of collagen turnover, namely serum galactosylhydroxylysyl-glucosyltransferase and plasma prolidase activity together with undulin, a novel extracellular matrix gfycoprotein. The study encompassed 15 healthy control subjects, 69 patients with various stages of schistosoma mansoni/hematobium infection ( 28 with early active infection and no organ involvement, 27 with hepatosplenic involvement and 14 with complications of portal hypertension) and 16 patients with alcoholic liver cirrhosis. Liver biopsies were obtained from 30 schistosomal patients for histopathological grading. Serum galactosylhydroxylysyl-glucosyltransferase was significantly increased in all clinical stages of schistosomiasis $(p<0.05)$ but normal in alcoholic cirrhosis. In contrast, plasma prolidase activity only showed a significant increase in early schistosomiasis $(p<0.01)$ but dropped to subnormal levels in advanced stages $(p<0.05)$. Patients with alcoholic cirrhosis exhibited the highest plasma prolidase activity $(p<0.001)$. Undulin was highly elevated both in alcoholic patients and in all schistosomal groups ( $p<0.001)$ and seems to be a rather good fibrotic markcr to distinguish between early and advanced schistcsomal stages.

We conclude that serum undulin may be a valuable non-invasive parameter to monitor the course of schistosomal and alcoholic liver disease.

\section{OXIX/7 946}

HEMODYMAAIIC CHARACTERISTICS OF HEPATOCEILULAR CARCIYOMA OBSERVED WITH DOPPIER SONOGRAPHY

H Kashida, K Minowa, H Tochio, K Shimada, M Hamada, S Tomita Kobe City General Hospital, Kobe, Japan

[Objective] In this study, hemodymamic characteristics of hepatocellular carcinoma (HCC) are analyzed with color and pulsed Doppler sonography. [Methods] The equipments we adopted were $5.0 \mathrm{MHz}$. The pulse repetition frequency was selected between $3 . \mathrm{C}$ and $6.0 \mathrm{KHz}$, and the width of sampling point was set to $1 \mathrm{~mm}$.

color flow signals were obtained in 160 out of 227 nodules of i!CCs. These flow signals were divided into three groups; that is, inflow, intratumoral, and outflow. They were subdivided according to the waveform pattern; pulsatile and constant. Flow velocity spectra were further analyzed in $88 \mathrm{HCCs}$ and were ccmpared with those in 30. metastatic liver tumor(Met)s and 9 hemangioma(Hem)s, using maximum velocity(Vmax) and pulsatility index(DI) as parameters. [Results] 1. Color Flow Imaging Inflow signals of HCCs ran along the capsule and branched off into the tumor. Large branches tended to run in the septa of the nooule. All of the inflow signals showed pulsatile pattern except for in 4 cases of early well-differentiated HCC, which were considered to be supplied by the portal vein instead of the hepatic artery. Intratumoral flow signals included both pulsatile and constant vaves. Even advanced HCCs which were totally supplied by the hepatic artery and not by the portal vein sometimes revealed constant flows within the turno. In some HCC cases we could detect outflow signals ruming along the capsule and draining into the portal vein. 2. Spectral Analysis Maximum Velocity and PI in HOCs were widely distributec. We consicier that this variety resulted from the irregular caliber changes and serpiginous running of the tumir vessels. In some cases of HCC, Virax was extremely rapid or PI wa:s very high. Actually, $85 \%$ of the hepatic tumors with Vmax of more than $50 \mathrm{~cm} / \mathrm{s}$ were $\mathrm{HCCs}$, and Vmax of greater than $70 \mathrm{~cm} / \mathrm{s}$ was diagnostic of HCC without exception. Also, 878 of the nodules with PI higher than that of normal hepatic artery were tCCs. [Conclusion] 1. Color flow inage bf typical HCCs consisted of inflow signals with pulsatile pattern, intratumoral signals of pulsatile or constant flow, and outflo: signals of constant wave. 2. Early, well-differentiated HCCs showed inflow signals with constant pattern, which is suggestive of portal blood supply. 3. Maximum velocity or pulsatility index can be parameters for differentiating HCCs from metastatic liver tumors or hemangiomas.

\section{OXIX/6 251}

PRIMARY HEPATOCELLULAR CARCINOMA IN PBC. RISK TO MALES ANO FEMALES. H.C. Mitchison, P.J. Kelly, M.F. Bassendine, O.F.W. James, Department of Medicine (Liver Group), Medical School, University of Newcastle-upon-Tyne, Newcastle-upon-Tyne, England, United Kingdom.

Primary hepatocellular cancer (HCC) is considered rare in patients with primary biliary cirrhosis (PBC). We have examined the development of HCC in 335 PBC patients followed for a median of 66.5 months (range $1-272$ ). There were 306 females and 29 males. During the follow-up period $36 \%$ (111) female patients, $45 \%$ (13) male patients died; $27 \%(82)$ and $24 \%$ (7) respectively of liver-related causes. Those with cirrhosis at diagnosis were more likely to die during follow-up $(33 / 127)$ $65 \%$, than those without $(41 / 208) 20 \%$. Eight patients developed HCC, four were male. The HCC patients were significantly older at diagnosis of PBC than the non-HCE patients (mean 67.5 years versus 58 years), $7 / 8$ had known cirrhosis. 1.3\% female patients developed HCC and $3.6 \%(4 / 111)$ of those who died had HCC. Four men, 13.9\% developed HCC, 38\% (4/13) of those who died. $7 / 8$ patients had raised alphafaetoprotein at time of diagnosis. In three this was a low (less than 1000) but rising level.

Logistic regression was used to calculate odds ratio for the effect of sex (adjusted or not adjusted for age). A second metinod was to use the dichotomous variable of development of HCC and length of follow-up in a Cox's proportional hazards model to examine the effect of sex (again adjusted or not adjusted for age). In the above four models increased risk of HCC development among males was between 8.7 and 12.0 .

We conclude: the approxinate 10-fold of HCC increase in PBC males is similar to that associated with male sex seen in the UK in cirrhosis in general; PBC men with cirrhosis have an HCC risk similar to other cirrhotic males. Alphafaetcprotein screening in PBC men is indicated.

\section{OXIX/8 1045}

IBNUNOHISTOCHEMICAL DETERMINATION OF P53 IN HEPATOCELLULAR CARCINOMA AND CORRELATION TO PCNA AND HBSAg EXPRESSION. L. Nakopoulou, I.Giannopoulou, A.Koureas, I.Psycharis and A.Archimadritis, Department of Pathology, University of Athens, Hedical school.

The overaccumulation of nuclear protein $p 53$ has been recognized in a variety of neoplasms, and is thought to occur as a result of point mutations in the p53 gene, which has been localized to chromosome $17 \mathrm{p}$. These mutations allow for the generation of stable p53 proteins which can be visualized with immunohistochemical staining. Proliferating cell nuclear antigen (PCNA Cyclin) is.proliferation - associated antigen present in proliferating normal and malignant cells. The aim of this study was to investigate the expression of p53 and PCNA in 50 cases of hepatocellular carcinoma (HCC) and adjacent tissue. Paraffin - embedded tissues were immunostained with ABC-complex method and monoclonal antibodies PAb 1801 PC10 and anti-HBsAg. Immunoreactive P53 and PCNA were observed in the nuclei of tumor cells and rarely in hepatocytes with high heterogeneity. Fourteen cases of HCC $(28 \%)$ were positive for $p 53$ and $17 / 50$ (34\%) HCC for PCNA (3/22, 6/22 Grade I $10 / 22,8 / 22$ Grade II, 1/6,3/6 Grade III respectively). Immunostain of P53 and PCNA on adjacent tissue sections revealed 553 expression in 8/36 and PCNA 4/36. The HBsAg was detected in paraffin sections in 8/36 HCC with adjacent tissue and which vere negative for 053 . Simultaneously positivite for 253 and PCNA was observed only in three HCC.

in conclusion: a) p53 expression was independent from PCNA in HCC which probably suggests that the mutated form of 053 is not correiated with the cell cycle of malignant cells b) p53 and PCNA were not related with histological grade and HBV infection. 